\title{
A CLÍNICA GESTÁLTICA E OS AJUSTAMENTOS DO TIPO PSICÓTICO
}

\author{
Gestalt Clinic and the Psychotic Adjustments \\ Clinica Gestalt y Ajustes Psicóticos
}

Lílian Cherulli de Carvalho

ILENO IZÍDIO DA Costa

\begin{abstract}
Resumo: O presente texto trata das acepções feitas pela abordagem da Gestalt-terapia aos fenômenos psicopatológicos, em especial àqueles denominados "psicóticos". Apresenta-se a tônica dada por Perls, Hefferline e Goodman - primeiros autores gestálticos aos modos peculiares de existir assumidos pelos sujeitos, qual seja a dos ajustamentos neurótico e psicótico, e a caracterização deste último, segundo os fundamentos epistemológicos da Gestalt-terapia. Finalmente, este trabalho traz a noção de sofrimento psíquico grave, como uma possibilidade de compreensão do fenômeno e resguardo da condição subjetiva intrínseca a ele.
\end{abstract}

Palavras-chave: Gestalt-terapia; Psicopatologia; Ajustamento do Tipo Psicótico; Sofrimento Psíquico Grave.

Abstract: This paper explores the Gestalt therapy meanings to psychopathological phenomena, especially those known as "psychotic". It shows the emphasis given by Perls, Goodman and Hefferline - first Gestalt authors - to the peculiar manner of existence produced by the subjects, which are the adjustment and the ongoing process of maintaining self-regulation, the neurotic and psychotic adjustments, and the characterization of the psychotic one according to the epistemological foundations of Gestalt-therapy. Finally, this work discusses the concept of serious psychic suffering, as an opportunity to understand and to keep the phenomenon and the subjective condition intrinsic to it.

Keywords: Gestalt-therapy; Psychopathology; Psychotic Adjustment; Serious Psychic Suffering.

Resumen: El presente estudio explora los significados del enfoque de la Terapia Gestalt a los fenómenos psicopatológicos, especialmente los conocidos como "psicóticos". Esto demuestra la importancia que Perls, Goodman y Hefferline - los primeros autores de la Terapia Gestalt - atribuyeron a la forma peculiar de existencia dada por los sujetos, es decir, los ajustes neuróticos y psicóticos, y la caracterización de este último de acuerdo con los fundamentos epistemológicos de la Terapia Gestalt. Por último, este trabajo incorpora el concepto de sufrimiento psíquico grave, como una oportunidad de comprender el fenómeno y proteger la condición subjetiva intrínseca a ella.

Palabras-clave: Terapia Gestalt; Psicopatología; Ajuste Psicótico; Sufrimiento Psíquico Grave.

“Cada homem será a medida de sua própria normalidade"

Kurt Goldstein (Augras, 2002, p. 12)

\section{Introdução}

A clínica gestáltica tem na noção de saúde seu primordial eixo norteador. É a crença nas potencialidades dos indivíduos e no seu direcionamento para a autorregulação que - via de regra - orienta as ações e planos terapêuticos.

Ao privilegiar as partes saudáveis do organismo em detrimento da idéia de um todo adoecido, tal "otimismo" garante uma posição diferenciada da Gestalt-Terapia no rol das abordagens terapêuticas. No entanto, é possível incorrer no risco de negligenciar situações de adoecimento, por vezes evidente.

Este artigo pretende discorrer sobre aspectos da compreensão gestáltica da patologia psíquica, especialmente com relação ao sofrimento psíquico grave, ordinariamente denominado psicótico. Admite-se, de antemão, o desafio de circunscrever um dos temas mais ricos e polêmicos da área psi. De certo modo, sobre a psicopatologia se assenta o surgimento da própria clínica psicológica e psiquiátrica, em um movimento semelhante às clássicas abordagens médicas. Assim, também se procura evidenciar certa resistência encontrada na área a respeito da discussão sobre a psicopatologia, ilustrada, principalmente, na limitação de referências teóricas específicas.

\section{Uma Questão de Ajustamento}

Desde o livro inicial da Gestalt-Terapia, Perls, Hefferline e Goodman (1997/1951) já tecem críticas a respeito da Psicologia por considerarem que todos os sistemas psicoterapêuticos, até então formalizados, referiam-se mais ao âmbito da anormalidade, dedicando muito pouco de suas teorizações ao que chamaram de "psicologia normal” (Holanda, 1998; Pimentel, 2003). A própria maneira limitada de se considerar os organis- 
mos isolados de outros ambientes impediu a criação de teorias adequadas à compreensão da normalidade e até da anormalidade. Nesse sentido, Perls et al. (1997/1951) proclamaram a Gestalt-Terapia como "a abordagem original, não deturpada e natural da vida; isto é, do pensar, agir e sentir do homem. O indivíduo comum, sendo criado numa atmosfera cheia de rupturas, perdeu sua Inteireza, sua Integridade” (p. 32).

Fritz Perls (2002) já havia trazido em Ego, Fome e Agressão sua concepção pessoal a respeito do ser saudável, metaforizada na situação alimentar de agressão, mastigação e assimilação do alimento (introjetos bons) pelo bebê e a concomitante rejeição de introjetos tóxicos. Em outras palavras, discernir elementos nutritivos e conseguir incorporá-los mediante um contato transformador, bem como rejeitar elementos tóxicos, bloqueando sua entrada no self ${ }^{1}$.

Fica claro, logo nos primeiros contatos com a abordagem gestáltica, que esta teoria visa às potencialidades do indivíduo e a sabedoria organísmica, mesmo em momentos críticos de sua existência. O estado saudável caracteriza-se por um processo permanente de manutenção de equilíbrios e de ajustamento às condições, sempre flutuantes, do meio interno e externo (Ginger \& Ginger, 1995). A sabedoria organísmica é uma constante e as situações de autorregulação são vetores de mudança, ocasionados por circunstâncias de desequilíbrio. Conforme o resgate de Clarkson (1993, citado por Holanda, 1998), justifica-se assim a estima da Gestalt-terapia a situações desestruturantes como fundamentais ao ajustamento ou transformações criativas. Sob esse aporte, pode-se afirmar que a psicopatologia, então, não é concebida como uma categoria limitante da experiência que apenas compromete o indivíduo, pois a Gestalt-terapia não negligencia aspectos saudáveis preservados por ele; antes, encara o processo psicopatológico por um viés positivo de ajustamento em situações insustentáveis ao self.

Augras (1986/2002), defendendo a Fenomenologia como via de acesso à patologia e ao psicodiagnóstico, afirma a normalidade como uma capacidade adaptativa frente a diversas situações da vida: "A saúde não é um estado, mas um processo, no qual o organismo vai se atualizando conjuntamente com o mundo, transformandoIhe e atribuindo-lhe significado à medida que ele próprio se transforma. (...) A saúde encontra-se nesse jogo de interações" (p. 11).

Na perspectiva gestáltica, saúde e doença constituem um processo dialético, cujas polaridades são definidas pelo estado de organização e desorganização da pessoa. É um continuum não definível operacionalmente, mas

\footnotetext{
1 Neste trabalho, adota-se o conceito de self como uma estruturaprocesso pela qual o sujeito está-no-mundo (Ribeiro, 1997; Tenório, 2003). A integração organizada de experiências confere a noção de "eu", flexibilizadas e reorganizadas continuamente devido aos intermináveis contatos realizados pelo sujeito. Assim, há algo que permanece no self, enquanto uma outra parte se modifica continuamente, mantendo preservada a autorreferência do sujeito.
}

onde se misturam contextos e adaptações (ou não) a eles. Holanda (1998) argumenta que o viés dialético na concepção gestáltica da psicopatologia remonta à psicologia humanista, força na qual se insere epistemologicamente a abordagem. Segundo o autor, baseada no Humanismo, a Gestalt-Terapia interessa-se pelo desenvolvimento máximo do potencial humano e parte da sua dimensão saudável pra compreendê-lo como um todo - o "ser" de devir. Nesse ínterim, aspectos conflitantes com o equilíbrio ou “adoecidos" já trazem inerentes em seu bojo a questão da salubridade, posto que o "ser-não" acontece.

A questão existencialista também pode ser recuperada, visto que o ser-sadio é quem, na condição de ser-nomundo, dispõe livremente do conjunto de possibilidades de relações que se apresentam diante de si no decorrer de sua existência. Neste sentido, o ser-doente define-se pelo aspecto de privação de escolha e liberdade quando comparado ao ser-sadio, ideal (Holanda, 1998).

Independentemente de qual seja o viés, se fundamentado em bases epistemológicas próprias, percebe-se que, sob o olhar da Gestalt-Terapia, a psicopatologia tem um aspecto eminentemente relacional, fruto de toda orientação dialógica que perpassa a abordagem. Nos dizeres de Holanda (1998, p. 41): “Adoecer', em Gestalt-Terapia, é estar em desarmonia relacional, seja com o mundo em geral, seja consigo mesmo". Instaura-se, pois, uma compreensão de relação psicopatológica e não apenas de uma patologia enclausurada no indivíduo.

Em Buber (2006), encontra-se claramente a tendência de se conceber uma psicopatologia relacional. Nele tem-se que o essencial à saúde do Eu é ser confirmado pelo Tu e também o inverso, mutuamente: "Confirmar o outro é aceitá-lo como ser de devir, é constituir o outro como parceiro de encontro, é acreditá-lo enquanto pessoa" (p. 43). A patologia seria, então, produto da desconfirmação. Como meio de promover a confirmação, a perspectiva buberiana evidencia o diálogo autêntico e o olhar para o sujeito segundo prismas que lhe sejam próprios enquanto outro ser vivente. A questão da responsabilidade também é tratada por ele, que a considera atributo da confirmação, a fé no poder que o outro tem sobre si mesmo.

Uma reunião dos aspectos aqui tratados, das concepções possíveis à Gestalt para tratar da questão da psicopatologia e, inclusive, considerando-a relacional por excelência, revela a possibilidade de também compreender este momento existencial sob o aporte peculiar do contato.

O processo de formação e transformação de figuras, em movimento fluido, confere o aspecto saudável ao indivíduo. Sua capacidade de perceber necessidades e entrar em contato com o meio externo e interno, retirando-se em seguida e retornando a um estado de ótimo de tensão define o processo de auto-atualização e realização do self (Ribeiro, 1985; Tenório, 2003).

A rigidez e o bloqueio no contato não implicam, necessariamente, que uma (psico)patologia esteja configu- 
rada como tal. Como anteviram Perls et al. (1997), em sua sabedoria o organismo se vale de resistências para a defesa do self quando este se encontra em situação de potencial ameaça ou impossibilidade de contato. Os bloqueios, como funções preservativas, são, num primeiro momento, estratégias saudáveis e criativas para a subsistência e proteção do self.

No entanto, retomando a noção de continuum tão cara aos pressupostos da Gestalt-terapia, os bloqueios podem acabar como formas psicopatológicas de contato, quando verificados como comportamentos rígidos ou maneiras cristalizadas e anacrônicas de interação com o mundo (Vasconcelos \& Menezes, 2005). Nesse sentido, Augras (1986/2002, p. 12) define que "patológico é o momento em que o indivíduo permanece preso à mesma estrutura, sem mudança e sem criação".

A questão da consciência é relevante no reconhecimento de um estado de bloqueio patológico posto que a awareness $^{2}$ de uma situação fortalece o indivíduo a discriminar figuras e fundos, percebendo sua dificuldade e permitindo, quando possível, a visualização ou criação de alternativas. De outro modo, sem que o indivíduo esteja aware nenhuma configuração, excitamento ou energia será sequer percebido e os ajustamentos criativos não acontecerão de forma satisfatória.

Os ajustamentos criativos resultam ou são uma resposta do sujeito com vistas à satisfação de uma necessidade. Para Perls et al. (1997) os ajustamentos criativos relacionam-se à autorregulação do organismo diante de uma demanda emergida, à uma gestalt que resolve um problema concreto. Dizem respeito a uma atitude dinâmica, transformadora da realidade e do próprio sujeito.

A forma de ajustamento do indivíduo pode acontecer em moldes neurótico ou psicótico, tomando a nomenclatura consagrada pela Psicanálise. Contudo, convém ressaltar o entendimento de que cada indivíduo existe-nomundo de uma maneira peculiar, inclusive quando em um ajustamento psicopatológico. A vivência, a significação e até a forma de apresentação de traços sintomáticos serão diferentes tanto quanto forem os indivíduos. O respaldo para uma diagnose vem, como já alertara Augras (1986/2002), do algo de coexistência na existência, que faz um indivíduo ser comunicável para os demais. É com esse princípio norteador que se pretende circunscrever compreensivamente o ajustamento do tipo psicótico.

\section{O Ajustamento do Tipo Psicótico}

A psicopatologia clássica descreve as psicoses, nomeadas de transtornos, segundo sinais e sintomas defini-

\footnotetext{
Segundo Yontef (1998, p. 215): "Awareness é uma forma de experienciar. É o processo de estar em contato vigilante com o evento mais importante do campo indivíduo/ambiente, com total apoio sensório-motor, emocional, cognitivo e energético. (...) A awareness é, em si, a integração de um problema". A ampliação do contínuo de awareness define-se como objetivo de toda terapia gestáltica.
}

dos por classificações psiquiátricas internacionais como o DSM-IV ou a CID-10. Essas classificações revelam critérios objetivos para o diagnóstico dos transtornos, evidenciando como patológicos os aspectos normalmente não-compartilhados por uma comunidade maior e que colocam o sujeito em um grau intenso de sofrimento psíquico e prejuízos psicossociais e afetivos.

Com relação aos transtornos psicóticos, Costa (2003, p. 72) afirma que "é necessário constatar (...) a impossibilidade da psicose como uma entidade única, ou mesmo como entidade nosográfica, sindrômica”. N. R. Carvalho (2006) concorda com a proposição ao assumir não haver na literatura definição plenamente satisfatória do conceito. No entanto, reconhece que as alterações psicológicas, na psicose, tendem a ser mais graves, intensas e comprometedoras ao indivíduo. A psicose é entendida, portanto, como uma categoria sintomatológica geral onde se encontram categorias nosológicas específicas, como a esquizofrenia - o principal transtorno psicótico -, seja pela freqüência ou pela importância clínica. Ressalte-se, ainda, que a principal característica das psicoses pode ser dada pela alteração no juízo de realidade do sujeito.

Segundo Dalgalarrondo (2000), o diagnóstico dos transtornos psicóticos envolve a sintomatologia positiva e negativa. Sintomas positivos são as manifestações produtivas do quadro psicótico e configuram os sintomas típicos como delírios, alucinações, comportamentos bizarros, agitação psicomotora, produções lingüísticas como neologismos e parafrasias, etc. Já os sintomas negativos caracterizam-se pela perda de funções psíquicas e empobrecimento global da vida psíquica e social do indivíduo. Como sintomas negativos têm-se o distanciamento afetivo, retração social, empobrecimento da fala e pensamento, abulia, avolição, lentificação psicomotora, entre outros.

A descrição dos sintomas é exaustiva, porém rasa, se se considerar a falta de questionamentos acerca da essência ou condições de surgimento e manutenção dos sintomas (Schneider, s/d). A circunscrição dos sintomas com base no campo existencial do sujeito veio a ser a principal diferença da psiquiatria tradicional com a psicopatologia fenomenológica.

Segundo Van den Berg (2000), três períodos podem ser evidenciados na história da psiquiatria fenomenológica. O primeiro foi instaurado por Karl Jaspers em 1913. Inspirado na obra de Wilhelm Dilthey, ele rompeu com o organicismo cartesiano em favor de uma postura compreensiva.

Dilthey, e consequentemente Jaspers, distinguiu a explicação pelos elementos e a observação compreensiva com caráter holístico e assim afirmou a Psicologia como interessada na observação e compreensão para uma posterior exposição de dados.

O segundo e o terceiro períodos da psiquiatria de orientação fenomenológica foram instaurados por L. Binswanger, em 1923 e 1933. Desses, a primeira etapa 
caracterizou-se pela reflexão acerca dos trabalhos de Husserl, já a segunda etapa, inspirada em Heidegger. Autores franceses - Minkowski, Merleau-Ponty, para citar alguns - são marcantes na história e afirmação da Fenomenologia aplicada à psiquiatria e psicopatologia.

A ruptura do paradigma psiquiátrico tradicionalista, fundamentado na ciência positivista, dualista e organicista, deu-se também com as críticas do movimento da antipsiquiatria, cujos principais argumentos reforçavam a inadequação da psiquiatria como uma área médica destinada ao tratamento das "doenças mentais". Os argumentos do movimento antipsiquiátrico podem ser bem sintetizados num de seus principais expoentes: Thomas Szasz. Segundo ele, "doença mental é uma metáfora", exatamente por não se encontrar em nenhum substrato físico do corpo humano (Szasz, 2002, citado por Costa, 2003). A Psiquiatria fundamenta-se em rótulos para sua ação terapêutica e desconsidera a verdadeira natureza das desordens mentais. Szasz (2002, citado por Costa, 2003) ainda é mais enfático ao argumentar que os médicos psiquiatras persuadem a comunidade científica e leiga a acreditar em seu poder de cura, num ato duplamente agressivo em que há corrupção da linguagem e redução da liberdade e responsabilidade individuais dos sujeitos.

É neste contexto de contracultura, de movimento antipsiquiátrico e da psiquiatria fenomenológica que a Gestalt-Terapia surge no contexto das abordagens psicológicas e estabelece um olhar teórico sobre a psicopatologia.

Na concepção gestáltica, a natureza da psicopatologia é a interrupção do processo de contato. Entende-se que quanto maior a rigidez na fronteira organismo-ambiente, mais severos os efeitos percebidos no comportamento e desenvolvimento do self. O continuum de gravidade dos efeitos, no entanto, é decorrente do grau de awareness que o sujeito mantém sobre o seu padrão de contato. Nas psicoses, a awareness encontra-se mais prejudicada do que nas neuroses, ainda que nestas o sujeito possa não dar conta de alterar o padrão de interação consigo e com o mundo.

Relacionando-as ao contato, enquanto forma de ajustamento criativo do organismo ao ambiente, Perls et al. (1997) diferenciaram neurose e psicose segundo a intensidade de perturbação na elasticidade da formação figura-fundo e o consequente fechamento de gestalten. Ao caracterizar as possibilidades de autorregulação do organismo, afirmaram que o ajustamento criativo poderia adquirir conjuntura tipicamente neurótica ou psicótica, delimitadas pela compreensão que faziam dos dois construtos.

Sobretudo Goodman (citado por Ginger \& Ginger, 1995) difere a neurose da psicose - e, portanto, os ajustamentos neuróticos e psicóticos - segundo a função do self mais prejudicada: na neurose, fala-se, prioritariamente, de uma perda nas funções Ego ou Personalidade, enquanto no ajustamento psicótico, a perda se dá na função Id.
Conforme Perls et al. (1997, p. 184):

(...) o Id, o Ego e a Personalidade são as etapas principais de ajustamento criativo: O Id é o fundo determinado que se dissolve em suas possibilidades, incluindo as excitações orgânicas e as situações passadas inacabadas que se tornam conscientes, o ambiente percebido de maneira vaga e os sentimentos incipientes que conectam o organismo e o ambiente. O Ego é a identificação progressiva com as possibilidades e a alienação destas, a limitação e a intensificação do contato em andamento, incluindo o comportamento motor, a agressão, a orientação e a manipulação. A Personalidade é a figura criada na qual o self se transforma e assimila ao organismo, unindo-a com os resultados de um crescimento anterior.

A partir do entendimento das funções do self, é possível afirmar que o ajustamento neurótico se reconhece em situações em que o sujeito está em contato com o ambiente e até mesmo reconhece o surgimento de figuras enquanto necessidades. No entanto, as respostas e atitudes a essas necessidades não são adaptadas ou satisfatórias.

Perls et al. (1997/1951) explicam a neurose como "evitação do excitamento espontâneo e a limitação das excitaÇões" (p. 235), como se o sujeito impedisse o contato em totalidade. A função Ego está prejudicada à medida que o self se boicota a fim de não agir (repressão), ou agir de maneira não atualizada, com vistas a satisfazer uma necessidade dominante. Há uma clara fixação do self em um projeto ideal, o que impede sua flexibilidade e fluidez de energia entre figuras-e-fundo. Já a função Personalidade encontra-se lesada tendo em vista que a incorporação ao self do contato finalizado não acontece. Impede-se a satisfação e a retirada, permanecendo o sujeito em um estado de constante desequilíbrio e tensão. Reforçam-se os aspectos cognitivos de auto-imagem do self relacionados ao fracasso, ao insucesso, ao desprazer, à não-realização, entre outras internalizações contrárias ao self ideal. Em suma, a neurose pode ser dita como a perda da espontaneidade no contato.

Já com uma perda na função Id instaura-se a psicose, “(...) a aniquilação de parte da concretude da experiência; por exemplo, as excitações perceptivas ou proprioceptivas. Na medida em que há qualquer integração, o self preenche a experiência (...). A fisiologia primária começa a ser afetada" (Perls et al., 1997, p. 235).

Ginger e Ginger (1995) ainda afirmam que o sujeito em ajustamento psicótico não responde claramente ao mundo exterior nem às suas próprias necessidades, como se estivesse desconexo da realidade, impedindo assim a ocorrência de ajustamento criador do organismo ao meio.

A função Id do self se relaciona aos momentos mais próprios do sentir pré-reflexivo. O self rege-se na função Id enquanto à disposição das sensações mais primárias, rudimentares e primitivas. Um bloqueio severo em qual- 
quer das etapas de contato relacionadas evidencia um padrão de comportamento que denota o desligamento de si e do mundo - posto que novas configurações sequer são sentidas, quanto mais notadas - numa interrupção profunda do fluxo de awareness. Por outro lado também pode acontecer uma estimulação excessiva dos sentidos, mantendo-se o self inundado por sensações que não adquirem significado, exatamente porque não são reconhecidas em outro nível de consciência. Nessa circunstância, o comportamento evidencia a falta de conexão entre o que é sentido visceralmente e o vivido emocional, assim como a falta de criatividade no ajustamento ficando ele restrito aos automatismos.

Consequentemente à perturbação da função Id, todas as outras são comprometidas em um movimento óbvio de cronificação do des-ajuste. Por esse olhar, a noção de Eu encontra-se comprometida porque o self não dá conta de integrar suas várias manifestações (Tenório, 2003). Sem uma atuação da função Ego, o self torna-se cada vez mais fragilizado, indefeso quanto aos introjetos tóxicos disponíveis no campo. A desorganização na função Personalidade impede que o self integre satisfatoriamente as experiências de contato, deixando abertas gestalten e inúmeras possibilidades falseadas de preenchimento.

Tão logo se atenha aos pressupostos dos fundadores e filosóficos da Gestalt-terapia, vê-se que a perspectiva relacional está no cerne da questão da psicopatologia. Não há ajuste em si mesmo, posto que ele só adquire sentido e contornos se concebido sobre um campo. As funções prejudicadas dizem respeito ao modo de funcionamento do self quando em situação de contato, que configura a impreterível relação do ser com o mundo. O contato é inevitável e, portanto, sempre o ser está em relação com alguma coisa. A rigor, relação é o elo que permite uma elaboração da psicopatologia sob diversos pontos de vista conceituais. Em última instância, ela mesma (a psicopatologia) é relacional.

Pelo processo de contato também é possível alcançar entendimentos sobre o ajustamento psicótico. Vasconcelos e Menezes (2005) identificaram como bloqueios em uma pessoa com diagnóstico de esquizofrenia: a) a fixação nas resistências do passado que não são mais alvos de tanta energia no presente; b) dessensibilização - percebida como uma indefinição de sentimentos, embotamento afetivo, baixa percepção dos sinais emitidos pelo próprio corpo ou acontecimentos à sua volta; c) deflexão - padrão de contato indireto e difuso. $\mathrm{O}$ modo de interação mostra que as relações são casuais e descompromissadas. O comportamento verbal tende a tornar-se pouco compreensivo, com discurso impessoal, polido, abundante em palavras e escasso em sentido. $\mathrm{O}$ sujeito banaliza ou subestima o valor e importância das sensações, inviabilizando o processo de reconhecimento de uma necessidade definida ou de delimitação de uma figura; d) retroflexão - a realidade externa não é suficientemente segura para investir energia e obter satisfação, encontrando-se impedido de enfrentá-la em função de temer possível decepção, prejudicar ou ser prejudicado. O fluxo de energia, então, é direcionado para um meio considerado pelo indivíduo como mais seguro: ele mesmo, o próprio corpo.

A partir das considerações de Vasconcelos e Menezes (2005), chegar a um modelo de bloqueios e fatores de cura combinados para compreender o que é fenomenologicamente concebido como ajustamento psicótico, tendo o Ciclo do Contato como referência, implica algumas ponderações. Primeiro, em virtude do entendimento do ajustamento psicótico como uma maneira peculiar a cada indivíduo de ser-no-mundo: cada sujeito vivencia o ajustamento por motivos e meios que lhe são próprios, sendo necessária uma descrição atenta em cada caso particular. Em segundo lugar, porque as diversas possibilidades de ser-no-mundo em um ajustamento psicótico têm diferenças consideráveis no que toca aos modos específicos de bloqueios; por exemplo, um sujeito com diagnóstico autista tem necessidades e gestalten incompletas muito diferentes de outro sujeito com diagnóstico esquizofrênico ou esquizoafetivo. Finalmente, porque se sabe que a postura fenomenológica em situação psicodiagnóstica é de encará-la de modo processual, preservando as características compatíveis com toda a fundamentação epistêmica da Gestalt-Terapia.

Diante do sujeito em ajustamento do tipo psicótico reconhece-se a necessidade de se flexibilizar que mecanismos de contato (saudável ou interrompido) e que esfera de funcionamento do self encontram-se afetados. O ajustamento do tipo psicótico coloca o sujeito diante da dificuldade de discernimento entre o que lhe é passível de entendimento e o que lhe foge às possibilidades de responsabilização. Dir-se-ia, então, que diante da desorganização do self, independente da função em que o contato seja primeiramente interrompido, todas as outras são afetadas na mesma intensidade. Id, Ego e Personalidade confundem-se no contato bloqueado e as novas experiências não podem ser integradas e assimiladas (Carvalho, 2008).

Outros autores gestálticos - ou cuja orientação filosófica esteja intimamente relacionada à epistemologia da abordagem - colaboram na exploração da psicopatologia de uma forma mais pragmática, por assim dizer.

Holanda (1998) afirma que a abordagem fenomenológica da psicopatologia tem por essência a compreensão da totalidade do ser humano e seu enredamento indissolúvel em uma rede de relações. $\mathrm{O}$ autor toma Buber como o meio primordial de tratar do assunto.

Segundo Buber (1974/2001), o diálogo autêntico exige que Eu e Tu estejam imbricados um ao outro, conectados relacionalmente. É pelo diálogo que se chega à constituição do Eu (e do Tu) e, para tanto, conforme exposto anteriormente, algumas atitudes o favorecem, tais como a abertura, reciprocidade, presença e responsabilidade (Holanda, 1998). Assim se expressa Buber (1974/2001): "Na conversação genuína, os dialogantes se confirmam 
mutuamente como pessoas, o que não significa aprovação do que o outro faz, mas de perceber o outro como existente e confirmá-lo como tal" (p. 43).

Buber (1974/2001) identifica as psicopatologias com a ausência de diálogo, colocando a gênese de grande parte delas na desconfirmação do Eu e na perda do referencial próprio, bem como em disfunções na presença. Para ele, a neurose implica a inautenticidade da presença, enquanto nas psicoses essa presença é esvaziada. Tendo o indivíduo tantas experiências de desconfirmação, podese dizer que ele se resguarda na segurança de seu isolamento a fim de impedir que nova desconfirmação venha a desintegrar seu self. Mais uma vez, reconhece-se o padrão psicótico como uma defesa do self às situações que o fariam perder-se de vez, um ajustamento não criativo às situações novas que se apresentam, porém potencialmente geradoras de maior sofrimento.

Adentrar no terreno da Fenomenologia é lidar com os mais variados aspectos na compreensão da psicopatologia:

Uns fazem da psicose uma alienação da condição humana. Outros explicam que não há nada nem pessoa a alienar; para esses, o homem é o significado de um discurso sem palavra (...). Neste infinito neutro (...) não há lugar para um eu capaz de presença e ausência (...). Mas a psicose não se entrega. Seu dramático testemunho (pathei mathos ${ }^{3}$ ) do que há de irredutível no homem (...). Também entendemos perceber na existência psicótica o existencial humano que a torna possível, mesmo onde a psicose é uma forma impossível disso (Maldiney, 1976, citado por Tatossian, 2006, p. 317).

Segundo Tatossian (2006), Binswanger, em sua Daseinsanálise inspira-se em Heidegger e trata da psicopatologia psicótica tomando por base os existenciais de presença e existência. Binswanger voltou-se à trajetória do indivíduo concreto, bem mais que aos traços supraindividuais das síndromes psicopatológicas, olhando para a íntima relação entre a biografia do sujeito e a conduta psicótica (Tatossian, 2006). De certo modo, a historicidade diz do tempo vivido, sendo uma forma de temporalidade humana, e também contextualiza os fenômenos psicóticos em termos da intencionalidade do ser-no-mundo. Sobre o assunto, Vasconcelos e Menezes (2005) entendem que o ser torna-se paralisado, ocorrendo uma transformação do ser-aí como historicidade em geral para uma forma a-histórica, apesar de que ainda se temporalize e espacialize de alguma maneira, já que sem isso não lhe teria garantido a existência.

Para De Waelhens (1990), a psicopatologia psicótica, em Binswanger, pode ser compreendida a partir de uma série de noções relativas a atitudes existenciais. Num pri-

"Aprender pelo sofrimento", nos dizeres de Ésquilo. meiro momento, o sujeito rompe com a coerência e evidências do mundo natural, esforçando-se para modificálas, porém sem sucesso uma vez que não as admite como de fato são. Ele assume um posicionamento arbitrário cujas experiências tornam-se cada vez mais falseadas e lacunares. Depois, em um segundo momento, o sujeito é surpreendido por idéias maniqueístas e por ideais irreais que conduzem à angústia insuportável. Por fim, no terceiro momento do processo, há uma tentativa de camuflagem e dissimulação do que é insuportável. Diante do insucesso, os sintomas típicos de delírios e alucinações tomam seu lugar fundamental de experiência nãoproblemática cujas posições irreconciliáveis não mais o dilaceram. Também em Binswanger nota-se o sentido de autopreservação que os sintomas adquirem e a expectativa de uma relação que seja compreensível aos outros, se os delírios e alucinações forem tomados como discurso que procura estabelecer uma comunicação.

Minkowski, por sua vez, compreende a psicopatologia psicótica sob a perspectiva espaço-temporal e da ruptura do contato vital com a realidade (De Waelhens, 1990; Augras, 1986/2002; Tatossian, 2006). Augras (1986/2002) afirma que a vivência do horizonte temporal, enquanto dimensões significativas do ser desaparece na psicose e essa perturbação essencial pode descrevê-la e diferenciá-la em termos diagnósticos: "cada estrutura peculiar diz respeito, em última análise, à maneira como o indivíduo se situa em relação à vivência do tempo e do espaço" (Minkowski, 1965, citado por Augras, 1986/2002, p. 36). Para a autora, a questão do espaço é dimensionada pelos limites do corpo e suas extensões, numa ontologia existencial. O espaço vital é imprescindível à sobrevivência e não pode ser invadido.

É possível visualizar os sintomas psicóticos relativos à vivência prejudicada de tempo e espaço como, por exemplo, no tocante às alucinações e delírios que, muitas vezes, expressam o temor do sujeito em ver-se invadido em seus sentidos (visuais, auditivos, sinestésicos) e percepções do campo (vivido como persecutório, somático ou em idéias de autorreferência, etc.). A rigidez tão forte de espaço e tempo chega aos limiares da repetição estereotipada autista e até a petrificação catatônica, como vividos possíveis ao sujeito.

A psicopatologia fenomenológica reconhece sintomas como manifestações comportamentais, mas seu foco é, na verdade, as modificações do vivido. À abordagem importa nem tanto o sintoma, mas o fenômeno: a maneira sui generis com que um indivíduo manifesta o seu vivido de ser-no-mundo (Tatossian, 2006). É esse o referencial que se une à Gestalt-terapia na tentativa de desenvolver um olhar sobre o fenômeno do ajustamento psicótico em si, mas, especialmente, ao sujeito que sofre.

Nesse ínterim, cabe a opção pela nomenclatura sofrimento psíquico grave do tipo psicótico. "Sofrimento psíquico grave" a fim de indicar não apenas o que está sob os desígnios da definição de psicose, mas para superá-la 
rumo ao apontamento de fenômenos existenciais, fenomenológicos, de caráter relacional e dinâmico que digam da angústia humana bem mais que a mera classificação nosográfica e categorial sintomatológica (Costa, 2003). Com esta opção, busca-se resgatar a dimensão natural de qualquer sofrimento humano, inclusive aqueles tidos como psicóticos.

Por sua vez, "tipo psicótico" por se entender que, sendo o ajustamento criativo uma função relacional, não há padrões pré-determinados para ele no curso de desenvolvimento. A despeito do quadro psicopatológico descrito como psicose, pela proposta do ajustamento do tipo psicótico, o sujeito não é rotulado segundo um padrão predefinido e específico de uma forma-de-ser patológica. É possível, diante do fundo relacional e histórico do sujeito, que o ajustamento adquira configurações mais típicas daquilo que se denomina psicótico ou neurótico no contexto psicológico/psiquiátrico. “Tipo psicótico” indica que uma disposição criativa encontra-se, em algum grau, potencialmente desorganizada; porém, o mesmo termo não limita a autorregulação do self nem estabelece uma linha psicopatológica evolutiva definitiva no curso da vida do sujeito.

Diante da complexidade exposta, se for possível apontar um denominador comum entre os raciocínios compreensivos, poder-se-ia chegar redutivamente ao hiato. Hiato entre a realidade vivificante e a experiência vivida; hiato entre o que é sentido e o que é significado conscientemente, nas vivências de tempo e espaço; hiato entre a lógica compartilhada e a lógica pessoal; hiato entre a linguagem e o compartilhamento de significados no campo social, hiatos...

\section{Referências}

Augras, M. (2002). O ser da compreensão: Fenomenologia da situação de psicodiagnóstico. Petrópolis: Vozes. (Originalmente publicado em 1986).

Buber, M. (2001). Eu e Tu. São Paulo: Centauro. (Originalmente publicado em 1974).

Buber, M. (2006). Do diálogo e do dialógico (M. E. de S. Queiroz \& R. Weinberg, Trad.). São Paulo: Perspectiva.

Carvalho, L. C. (2008). A Intervenção Precoce nos Ajustamentos do tipo Psicótico e a Clínica Gestáltica: ensaios preliminares. Dissertação de Mestrado em Psicologia e Cultura, Universidade de Brasília, Brasília.

Carvalho, N. R. (2006). Primeiras crises psicóticas: identificação de pródomos a partir de pacientes e familiares. Dissertação de Mestrado, Universidade de Brasília, Brasília.

Costa, I. I. (2003). Da fala ao sofrimento psíquico grave. Brasília: ABRAFIPP.

Dalgalarrondo, P. (2000). Psicopatologia e Semiologia dos Transtornos Mentais. Porto Alegre: Artmed.
De Waelhens, A. (1990). A Psicose: ensaio de interpretação analítica e existencial. Rio de Janeiro: J. Zahar.

Ginger, S. \& Ginger, A. (1995). Gestalt: uma terapia do contato. São Paulo: Summus.

Holanda, A. F. (1998). Saúde e doença em Gestalt-Terapia: aspectos filosóficos. Estudos de Psicologia, 15, 2, 29-44.

Perls, F. (2002). Ego, Fome e Agressão. São Paulo: Summus.

Perls, F., Hefferline, R., \& Goodman, P. (1997). Gestalt-Terapia. São Paulo: Summus. (Originalmente publicado em 1951).

Pimentel, A. (2003). Psicodiagnóstico em Gestalt-Terapia. São Paulo: Summus.

Ribeiro, J. P. (1985). Gestalt terapia: refazendo um caminho. São Paulo: Summus.

Schneider, K. (1975). Psicopatologia Clínica (7ª Ed.). São Paulo: Mestre Jou.

Tatossian, A. (2006). A Fenomenologia das Psicoses. São Paulo: Escuta.

Tenório, C. M. D. (2003). Os transtornos da personalidade histriônica e obsessiva-compulsiva na perspectiva da GestaltTerapia e da teoria de Fairbairn. Tese de Doutorado em Psicologia Clínica, Universidade de Brasília, Brasília.

Van den Berg, J. H. (2000). O Paciente Psiquiátrico. Campinas: Livro Pleno.

Vasconcelos, A. C. \& Menezes, S. M. M. (2005). Processo diagnóstico da esquizofrenia: uma visão gestáltica. Revista do XI Encontro Goiano da Abordagem Gestáltica. Anais "Presença e Existência", 215-231.

Lílian Cherulli de Carvalho - Mestre em Psicologia Clínica e Cultura pela Universidade de Brasília (UnB); Especialista em Gestalt-Terapia pelo Instituto de Gestalt-Terapia de Brasília (IGTB). Profissional associada ao Grupo de Intervenção Precoce (GIPSI/IP/UnB). E-mail: liliancc@hotmail.com

Ileno Izídio da Costa - Professor Adjunto do Instituto de Psicologia da Universidade de Brasília; Doutor em Psicologia Clínica (Universidade de Brasília/Warwick University, Inglaterra); Master of Arts em Filosofia e Ética da Saúde Mental (Warwick/Inglaterra); Coordenador da Clínica Escola e do Grupo de Intervenção Precoce nas Primeiras Crises do Tipo Psicótica (GIPSI) do Instituto de Psicologia da UnB. Endereço Institucional: Universidade de Brasília, Instituto de Psicologia, Departamento de Psicologia Clínica. Campus Universitário, ICC Sul, Bloco A - Asa Norte. CEP 70.910-900, Brasília, DF. E-mail: ileno@unb.br

Recebido em 04.10.09 Aceito em 15.12.09 